\title{
Unveiling the Role of Prolactin and its Receptor in Male Reproduction
}

\author{
Authors \\ Sanketa Raut*, Sharvari Deshpande*, Nafisa H. Balasinor
}

\begin{abstract}
Affiliation
Neuroendocrinology Department, National Institute for Research in Reproductive Health - ICMR, Mumbai, India
\end{abstract}

Key words

prolactin, prolactin receptor, spermatogenesis, testis, male reproduction

received $\quad 23.10 .2018$

accepted $\quad 12.02 .2019$

Bibliography

DOI https://doi.org/10.1055/a-0859-1144

Published online: 6.3.2019

Horm Metab Res 2019; 51: 215-219

(c) Georg Thieme Verlag KG Stuttgart · New York

ISSN 0018-5043

Correspondence

Nafisa H. Balasinor

Neuroendocrinology Department

National Institute for Research in Reproductive Health - ICMR

Jehangir Merwanji Street, Parel

Mumbai

400012

Tel.: + 91/22/24192 025, Fax: + 91/22/24139412

balasinorn@nirrh.res.in

\begin{abstract}
Prolactin is a peptide hormone known to have multiple functions. However, the role of prolactin has been extensively studied only in female physiology and its function in male reproduction still remains majorly unexplored. Studies in rodents and humans have demonstrated the presence of prolactin and its receptor in testes, thereby suggesting a possible role during spermatogenesis. Experimental evidences from prolactin and prolactin receptor deficient male rodent models as well as studies done in hypo- and hyper-prolactinemic males hint at neuroendocrine and reproductive abnormalities. Nonetheless, there still remains a lot of ambiguity on the exact role of prolactin and its receptor in male reproduction. This review summarizes in depth on the role of prolactin in spermatogenesis.
\end{abstract}

\section{Introduction}

Prolactin (PRL) is a polypeptide hormone, which is primarily secreted by lactotropic cells of the pituitary [1,2]. Juggling between varied functions, prolactin is known to have more actions than all the other pituitary hormones together. It has multifaceted roles like osmoregulation, growth and development, endocrine functions, metabolism, neurobiological functions, immunomodulation as well as in reproduction. Believed to be an important factor in female reproductive physiology, the role of this hormone has been intensively studied in females and is involved in lactation, mammary gland development, maintenance of corpus luteum, and maternal behavior [1,2]. Prolactin receptors are also present in male reproductive organs, the precise role or any specific target organ of this hormone in male reproductive physiology remains unknown. Late-

* Equal contribution. ly, several animal and human studies have shown that prolactin positively modulates various aspects in testicular function hinting at a crucial role in male reproduction.

The release of prolactin is regulated by a wide variety of factors secreted from the Hypothalamus-Pituitary-Gonadal axis (HPG axis). The systemic levels of prolactin depends on the actions and effects of these factors which can be inhibitory or stimulatory in nature. Classically, prolactin and dopamine are known to be antagonistic in nature. Prolactin regulates its own release via a short feedback mechanism by acting on prolactin receptors on hypothalamic dopaminergic neurons. This causes the release of dopamine which has an inhibitory effect on lactotrophs via its cognate D2 receptor leading to prolactin suppression. This demonstrates that dopamine has a crucial role in regulating prolactin levels $[3,4]$. Prolactin is believed to control the gonadal function indirectly by regulating the release of gonadotropins from the pituitary or by directly increas- 
ing the concentration of $\mathrm{LH}$ receptors on Leydig cells in the testes. All these effects show that prolactin works at neuroendocrine level and has a pivotal role in male reproduction. This review summaries the existing evidences and work done on prolactin in males and tries to put light on the actions of prolactin in male reproduction.

\section{Prolactin and Receptor Localization in Testis}

\section{Prolactin}

Prolactin is primarily secreted by the anterior lobe of pituitary, but there are extra-pituitary sites such as placenta, spleen, skin, and lachrymal gland $[5,6]$. The most abundant form of prolactin found is of $23 \mathrm{kDa}$, although multiple variants have been identified in mammals. These variants are a result of alternative splicing and post-translational modifications such as glycosylation, phosphorylation, dimerization, and polymerization [2,7].

Testis comprises of 2 cell types; somatic cells (Sertoli, Leydig and pertitubular myoid cells) and germ cells (spermatogonia, spermatocytes, round, elongating, and elongated spermatids). Spermatogenesis is a process, which is regulated by cross-talk between the 2 cell types. It can be divided into 4 distinct phases; mitosis (proliferation of spermatogonia), meiosis (reductional division from primary spermatocyte to round spermatids), spermiogenesis (cytodifferentiation of round spermatids to spermatozoa), and spermiation (release of spermatozoa into the lumen) [8]. Prolactin regulates various testicular functions by modulating the FSH and LH receptors on Sertoli and Leydig cells, respectively. It is also involved in meiotic division in germ cells [9-12]. By immunohistochemistry Roux et al. demonstrated the presence of prolactin in interstitial cells, Sertoli cells and germ cells [13]. However, it was unclear if prolactin was produced, secreted or simply stored in the testes. Another study carried out, observed the transcript and protein levels of PRL in testis. PRL transcript was mainly found in Leydig cells, spermatogonia, pachytene and preleptotene spermatocytes in both prepubertal and adult mice [14]. Guillaumot and Benahmed showed the presence of PRL transcript in the Sertoli cell isolated in vitro after FSH treatment [15]. It was also shown that the levels in testis were lower as compared to the pituitary levels. Using immunoblotting and immunofluorescence, protein levels were detected in testis as well as sperm [14].

\section{Prolactin receptor}

Prolactin acts via a transmembrane receptor, PRL-R belonging to class 1 cytokine receptor superfamily. This family includes receptor for various interleukins, leptin, erythropoietin etc. Prolactin receptor is closely related to growth hormone receptor (GHR) sharing about $30 \%$ sequence identity as well as sharing structural and functional features. Although all these receptor are genetically unique, they have consensus amino acid sequences in intracellular as well as extracellular domains which are highly conserved in all of them. The receptor has multiple isoforms and different isoforms have been identified in different tissues in different species $[16,17]$.

One of the reason why the role of prolactin is difficult to fathom in male reproduction is because there is a lot of contradiction in the data available. Wahlstrom et al. demonstrated the presence of prolactin receptor in rat testes, however, negative staining was observed in human testes [18]. Contradictorily, the presence of prolactin receptor was shown in germ cells of human testes mainly in pachytene spermatocytes, secondary spermatocytes, round spermatids (RS), and elongating spermatids. Spermatogonia, leptotene, zygotene, diplotene spermatocytes, and elongated spermatids along with Sertoli cells were devoid of prolactin receptors. Weak signal was observed in Leydig cells [19]. Hondo et al. have observed prolactin receptor transcripts in all spermatogenic cells by in situ hybridization except in RS [20] (• Fig. 1).

\section{Signalling pathway}

Prolactin receptor has 2 distinct domains; extracellular and intracellular domain. The extracellular domain has a ligand binding site to which prolactin binds and bring about dimerization of the receptor. Intracellular domain is responsible for initiating the signalling cascade for prolactin receptor. This occurs via transphosphorylation of Janus kinase (Jak2), which is constitutively present on the intracellular domain of the receptor. Jak2 brings about phosphorylation of other tyrosine residues on the receptor. Phosphorylated tyrosine residues acts as binding site for transducer molecules like signal transducer and activator of transcription (STATs) which binds via SH2 domain. Different types of STATs, mainly STAT (1, 3, $5 \mathrm{a}, 5 \mathrm{~b})$ are involved in activation of downstream targets. Prolactin receptor also activates Ras/Raf/MAPK (mitogen-activated protein

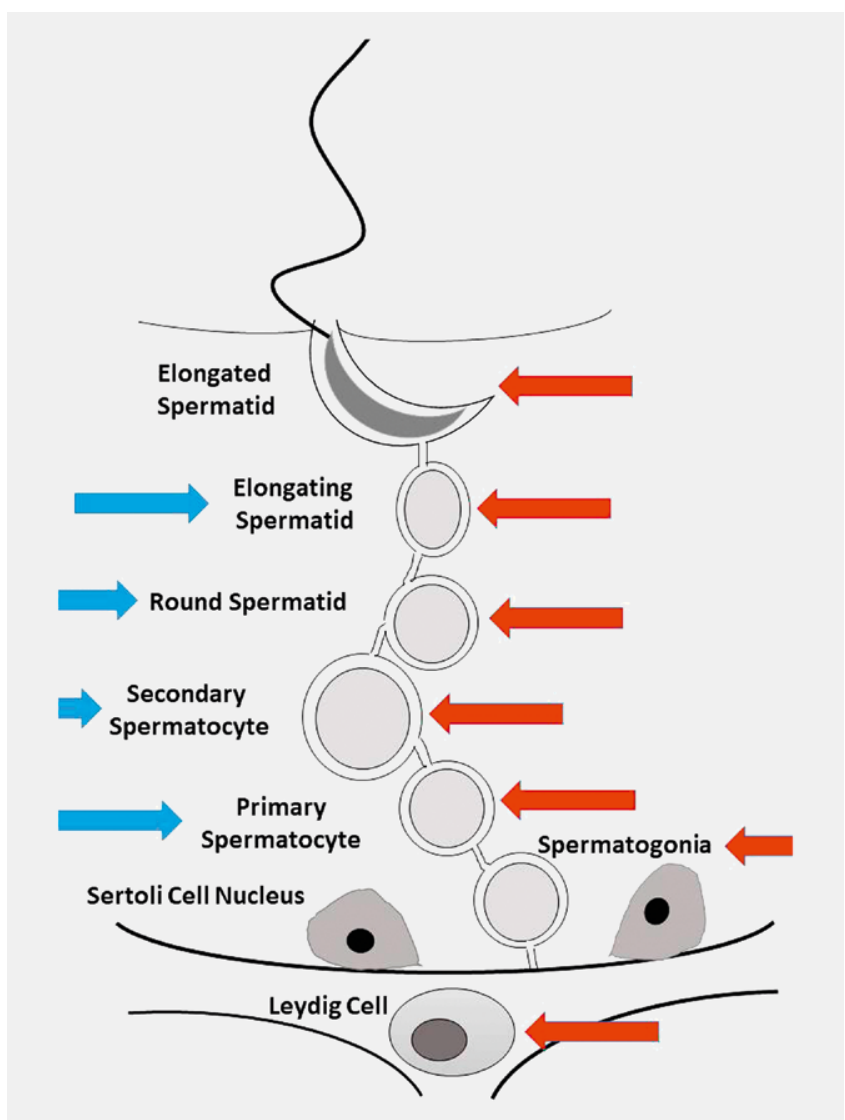

- Fig. 1 Diagrammatic representation illustrating the presence of prolactin receptor in the testes. Red arrow indicates transcript and blue arrow indicates protein localization. 
kinase) pathway by stimulating a wide variety of transcription factors or early genes by phosphorylation leading to various genomic effects which has involvement in various biological functions [1,2].

\section{Rodent Models to Study Prolactin and Its Receptor Functions}

\section{PRL agonists and antagonists}

The significance of prolactin and its receptor in male reproduction remains debatable since very few studies have characterized the effect of over or under expression of the same. Nag et al. studied the effect of prolactin suppression by administering dopamine receptor agonist, 2-bromo- $\alpha$-ergocriptine to adult male rats [12]. They observed significant reduction in reproductive organ weights and serum prolactin level. Whereas serum LH levels were increased and FSH remained unaffected. Upon exogenous treatment of prolactin to $\mathrm{PRL}$ deficient male rats resulted in the restoration of the effects observed. Enumeration of spermatogenic cells from stage VII of seminiferous epithelium showed significant reduction in the RS population, however the other spermatogenic cells were unaffected. The RS count was restored after prolactin supplementation [12]. Another study carried out by Bartke in hypophysectomized mice has also shown the role of prolactin during spermatogenesis. The study showed significant reduction in RS population in hypophysectomized hereditary dwarf mice and upon prolactin treatment observed an increase in the same [21]. These evidences highlights the potential role of prolactin in meiosis. Also studies in our lab have shown that upon estrogen treatment to adult male rats, higher serum levels of prolactin were observed [22,23]. Further, upon estrogen receptor (ER $\alpha$ and $E R \beta$ ) specific ligands treatment also showed high prolactin levels followed defects in spermatogenesis process. ER $\alpha$ agonist was responsible for affecting spermiogenesis whereas ER $\beta$ was involved affecting spermiation [24, 25]. Chromatin Immunoprecipitation (ChIP) Sequencing for estrogen receptor ER $\alpha$ and ER $\beta$ in germ cells of adult male rats showed significant enrichment of genes involved in prolactin pathway suggesting a plausible role of prolactin in spermatogenesis (Unpublished observations). However, further studies are on-going to validate our findings.

Gill-Sharma et al. studied the effect of fluphenazine, a known dopamine receptor antagonist which causes hyperprolactinemia in adult male rats [26]. No effects were seen in the reproductive organ weights, however, serum LH and FSH levels were reduced. No effects were observed in serum testosterone and estradiol levels. The fertility studies showed significant reduction in potency, implantation size and litter size. Further studies showed reduction in spermiogenesis related proteins like transition proteins, protamine, CREMt, ABP protein levels in the testes. These results suggests that hyperprolactinemia causes reduction in FSH levels without any change in testosterone levels. The reduction in FSH resulted in lower levels of cAMP which may have led to dysregulation of downstream spermiogenesis related genes which are involved in chromatin condensation [27]. However, this study did not quantitate the RS population therefore it cannot be speculated if the reduction in protein levels is due to true reduction in RS population or not. In addition, direct effects of hyperprolactinemia independent of FSH effect cannot be ruled out as prolactin receptors are present in testicular cells. Further studies are required to validate the findings. Hyper- or hypo-prolactinemia effects on gonadotropins can be possibly due to secondary changes brought about by prolactin on hypothalamus and not due to effect on the pituitary. Hyperprolactinemia in rats lead to decrease in LH levels. However, prolactin is known to increase $\mathrm{LH}$ receptors and its responsiveness in the testes [9]. This explains why the plasma testosterone levels were not affected in hyperprolactinemia despite decrease in LH levels in rodents.

\section{Prolactin and its receptor knockouts}

Steger et al. developed PRL KO male mice to study their neuroendocrine and reproductive functions. Compared to wild type males the PRL KO males showed reduction in dopamine, LH, and FSH levels. However, no effect was seen on testosterone levels and fertility parameters [28]. This study corroborates with the findings observed by Bartke in hypophysectomized hereditary dwarf mice [21].

Another way to study prolactin function was to knockout its receptor. Binart et al. carried out disruption of prolactin receptor gene (PRLR $\mathrm{KO}$ ) in mice. No effects were observed on body weights, reproductive organ weights, fertility parameters, hormonal profile, testicular morphology, and sperm parameters. Overall no changes were observed in the absence of prolactin and its receptor in reproductive functions [29]. It would be interesting to study the double knockouts for both prolactin and its receptor to get a clearer picture of the exact role in neuroendocrine and reproductive functions. Surprisingly, an effect is observed on the reproductive function when prolactin is knockdown [12] but not when it is completely knocked out [29]. This suggests that abnormal level of prolactin affects the reproductive function but there may be some alternate mechanism, for example, growth hormone pathway, to compensate in its absence [14].

\section{Human studies (hyper/hypoprolactinemia and its effects)}

In the past few years several studies have shown the relation between hypo- and hyper-prolactinemia and male reproductive behavior in humans. Hyperprolactinemia can be idiopathic, tumor or drug induced and is one of the causes leading to altered sexual behavior like erectile dysfunction (ED) and loss of libido [30]. It is also speculated that it can cause endocrine disturbances leading to abnormal levels of gonadotropins and testosterone. Buvat et al. showed that $88 \%$ of males who are hyperprolactemic had erectile dysfunction [31]. Carani et al. did not observe any symptoms of ED in hyperprolactemic males as compared to control individuals [32]. However, this discrepancy could be due to small sample size. When screened for hyperprolactinemia in ED patients, very few percent of them were found to be hyperprolactemic.

Boucher et al. studied the effects of bromocriptine in individuals with hyperprolactinemia and demonstrated that the prolactin secretion was lowered and spermatogenesis which was altered was restored back to normal [33]. Another study by Merino et al. showed high levels of prolactin in patients with different infertile conditions like oligozoospermia, asthenozoospermia and azoospermia [34]. However upon treatment with prolactin antagonist, bromocriptine the serum levels of prolactin remained unaltered. These suggest that there are not sufficient evidences to prove if hyperprolactinemia leads to ED. The role of bromocriptine as a prol- 


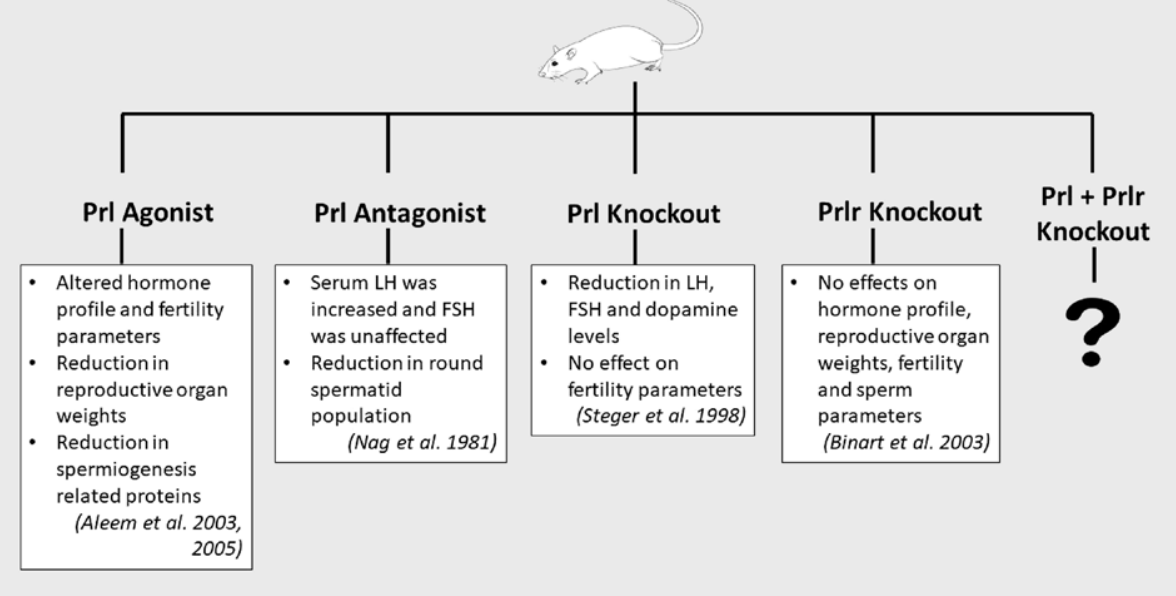

- Fig. 2 Schematic representation of different rodent models, which are deficient in prolactin and its receptor.

actin antagonist is well established and is used in treatment of ED. Colao et al. studied the effect of dopamine agonist, quanagolide in patients with macroprolactinoma and microprolactinoma which showed high levels of prolactin and lower testosterone levels along with low sperm count and sperm motility [35]. However, after treatment, the prolactin levels were lowered and the other parameters were return to basal levels. Similar results were obtained after treatment with cabergoline which is also a dopamine agonist [36, 37].

On the other extreme, very few studies have shown the association between hypoprolactinemia and sexual dysfunction. Corona et al. demonstrated that individuals with sexual dysfunction showed lower levels of prolactin and higher risk of ED and premature ejaculation [38]. Low prolactin levels suggests that there could be an increase in the dopamine levels or could be due to altered serotonin pathway. Gonzales et al. showed a strong relationship with hypoprolactinemia and diminished sperm motility. However no effects were observed on basic sperm parameters [39].

\section{Concluding Remarks}

Prolactin is involved in a number of different biological functions including reproduction [1,2]. The role of prolactin has been majorly explored in female reproduction, however, there is a paucity of information of its involvement in male reproduction. Current rodent models for prolactin and its receptor knockouts point at the fact that there are a lot of ambiguities in reproductive parameters in males suggesting that the mechanism by which prolactin and its receptor acts on spermatogenesis still remains blurred. Till date, the strategies used by the researchers include knocking out either prolactin or its receptor $[28,29]$. The major disadvantage of using these models is that, the absence of prolactin can be compensated by other molecules such as hormones or cytokines, also, in the absence of prolactin receptor the different isoforms of prolactin can act via different homologous receptor [14]. Using the current models to study the exact role of prolactin is difficult due to its compensatory nature and therefore a better strategy is required to study prolactin, for example, in the development of double knock- out rodent models $(\mathrm{Prl}+\mathrm{Pr} \mathbf{r})$ ( $\vee$ Fig. 2). This will further expand our understanding of functioning of this multitasking hormone.

\section{Acknowledgements}

The authors would like to acknowledge National Institute for Research in Reproductive Health (ICMR) for their support.

\section{Funding}

This work [REV/668/08-2018] did not receive any specific grant from any funding agency in the public or not-for-profit sector.

\section{Conflict of Interest}

The authors confirm that there is no conflict of interest.

References

[1] Bole-Feysot C, Goffin V, Edery M et al. Prolactin (PRL) and its receptor: Actions, signal transduction pathways and phenotypes observed in PRL receptor knockout mice. Endocr Rev 1998; 19: 225-268

[2] Freeman ME, Kanyicska B, Lerant A et al. Prolactin: Structure, function, and regulation of secretion. Physiol Rev 2000; 80: 1523-1631

[3] Gill-Sharma MK. Prolactin and male fertility: The long and short feedback regulation. Int J Endocrinol 2009;Article ID 687259; http:// dx.doi.org/10.1155/2009/687259

[4] Hermanns U, Hafez SE. Prolactin and male reproduction. Arch Androl 1981; 6: 95-125

[5] Harigaya T, Komori M, Kawakami T et al. Expression of prolactin gene in mouse placenta during late pregnancy. Endocr J 1997; 44: 155-161

[6] Horiguchi K, Yagi S, Ono $\mathrm{K}$ et al. Prolactin gene expression in mouse spleen helper T cells. J Endocrinol 2004; 183: 639-646

[7] Sinha YN. Structural variants of prolactin: Occurrence and physiological significance. Endocr Rev 1995; 16: 354-369 
[8] Hess RA, de Franca LR. Spermatogenesis and cycle of the seminiferous epithelium. Molecular mechanisms in spermatogenesis 2009. New York: Springer; 2009: 1-15

[9] Dombrowicz D, Sente B, Closset J et al. Dose-dependent effects of human prolactin on the immature hypophysectomized rat testis. Endocrinology 1992; 130: 695-700

[10] Purvis K, Clausen PF, Olsen A et al. Prolactin and Leydig cell responsiveness to LH/hCG in the rat. Arch Androl 1979; 3: 219-230

[11] Guillaumot P, Tabone E, Benahmed M. Sertoli cells as potential targets of prolactin action in the testis. Molecular and cellular endocrinology 1996; 122: 199-206

[12] Nag S, Sanyal S, Ghosh KK et al. Prolactin suppression and spermatogenic developments in maturing rats. A quantitative study. Hormone Res Paediatr 1981; 15: 72-77

[13] Roux M, Martinat N, Richoux JP et al. Histoimmunological identification of a prolactin-like substance in rodent testis. Cell Tissue Res 1985; 240: 663-667

[14] Ishida M, Yoshida M, Fukuta S et al. Analysis of prolactin gene expression and cleaved prolactin variants in the mouse testis and spermatozoa. J Reprod Develop 2010; 56: 567-574

[15] Guillaumot P, Benahmed M. Prolactin receptors are expressed and hormonally regulated in rat Sertoli cells. Mol Cell Endocrinol 1999; 149: $163-168$

[16] Binart N, Bachelot A, Bouilly J. Impact of prolactin receptor isoforms on reproduction. Trends Endocrinol Metab 2010; 21: 362-368

[17] Ouhtit A, Morel G, Kelly PA. Visualization of gene expression of short and long forms of prolactin receptor in rat reproductive tissues. Biol Reprod 1993; 49: 528-536

[18] Wahlstrom T, Huhtaniemi I, Hovatta O et al. Localization of luteinizing hormone, follicle-stimulating hormone, prolactin, and their receptors in human and rat testis using immunohistochemistry and radioreceptor assay. J Clin Endocr Metab 1983; 57: 825-830

[19] Hair WM, Gubbay O, Jabbour HN et al. Prolactin receptor expression in human testis and accessory tissues: Localization and function. Mol Human Reprod 2002; 8: 606-611

[20] Hondo E, Kurohmaru M, Sakai S et al. Prolactin receptor expression in rat spermatogenic cells. Biol Reprod 1995; 52: 1284-1290

[21] Bartke A. Effects of prolactin on spermatogenesis in hypophysectomized mice. J Endocrinol 1971; 49: 311-316

[22] Gill-Sharma MK, D'souza S, Padwal V et al. Antifertility effects of estradiol in adult male rats. J Endocrinol Invest 2001; 24: 598-607

[23] D'Souza R, Gill-Sharma MK, Pathak S et al. Effect of high intratesticular estrogen on the seminiferous epithelium in adult male rats. Mol Cell Endocrinol 2005; 241: 41-48
[24] Dumasia K, Kumar A, Kadam L et al. Effect of estrogen receptor-subtype-specific ligands on fertility in adult male rats. J Endocrinol 2015; 225: $169-180$

[25] Dumasia K, Kumar A, Deshpande S et al. Differential roles of estrogen receptors, ESR1 and ESR2, in adult rat spermatogenesis. Mol Cell Endocrinol 2016; 428: 89-100

[26] Gill-Sharma MK, Aleem M, Sethi G et al. Antifertility effects of fluphenazine in adult male rats. J Endocrinol Invest 2003; 26: 316-326

[27] Aleem M, Choudhari J, Padwal V et al. Hyperprolactinemia affects spermiogenesis in adult male rats. J Endocrinol Invest 2005; 28: 39-48

[28] Steger RW, Chandrashekar V, Zhao W et al. Neuroendocrine and reproductive functions in male mice with targeted disruption of the prolactin gene. Endocrinology 1998; 139: 3691-3695

[29] Binart N, Melaine N, Pineau C et al. Male reproductive function is not affected in prolactin receptor-deficient mice. Endocrinology 2003; 144: $3779-3782$

[30] Buvat J. Hyperprolactinemia and sexual function in men: A short review. Int J Impot Res 2003; 15: 373

[31] Buvat J, Lemaire A, Buvat-Herbaut $M$ et al. Hyperprolactinemia and sexual function in men. Horm Res Paediatr 1985; 22: 196-203

[32] Carani C, Granata RM, Fustini MF et al. Prolactin and testosterone: their role in male sexual function. Int J Androl 1996; 19: 48-54

[33] Boucher D, Hermabessiere J, Doly M et al. Prolactin secretion in infertile men before and after treatment with bromocriptine. Ann Biol Anim Biochim Biophys 1997; 17 (3B): 483-498

[34] Merino G, Carranza-Lira S, Martinez-Chéque JC et al. Hyperprolactinemia in men with asthenozoospermia, oligozoospermia, or azoospermia. Arch Androl 1997; 38: 201-206

[35] Colao A, De Rosa M, Sarnacchiaro F et al. Chronic treatment with CV 205-502 restore the gonadal function in hyperprolactinemic males. Eur J Endocrinol 1996; 135: 548-552

[36] De Rosa M, Colao A, Di Sarno A et al. Cabergoline treatment rapidly improves gonadal function in hyperprolactinemic males: A comparison with bromocriptine. Eur J Endocrinol 1998; 138: 286-293

[37] Colao A, Vitale G, Cappabianca P et al. Outcome of cabergoline treatment in men with prolactinoma: Effects of a 24-month treatment on prolactin levels, tumor mass, recovery of pituitary function, and semen analysis. J Clin Endocrinol Metab 2004; 89: 1704-1711

[38] Corona G, Mannucci E, Jannini EA et al. Hypoprolactinemia: A new clinical syndrome in patients with sexual dysfunction. J Sex Med 2009; 6: $1457-1466$

[39] Gonzales GF, Velasquez G, Garcia-Hjarles M. Hypoprolactinemia as related to seminal quality and serum testosterone. Arch Androl 1989; 23: $259-265$ 